\title{
ON THE INVERSE-CLOSEDNESS OF MATRIX SUBALGEBRAS
}

\author{
NAHUM KRUPNIK
}

Abstract. In this short article we construct a counterexample, which gives a negative answer to an old question, formulated in several publications, on inverse-closedness of matrix subalgebras. We also present and prove several related results.

Mathematics subject classification (2010): Primary 47A11, Secondary 45E10.

Keywords and phrases: Banach algebras, inverse-closed subalgebras of Banach algebras.

\section{REFERENCES}

[1] Bruce A. BARnes, Questions concerning matrix algebras and invariance of spectrum, Proc. Indian Acad. Sc. (Math. Sci) February 2003. pp. 71-76.

[2] I. Gohberg And N. KRUPNIK, One-Dimensional Linear Singular Integral Equations, Vol I, OT 53, Birkhäuser Verlag (1992).

[3] N. KRUPNIK, Banach Algebras with Symbols and Singular Integral Operators, OT 26, Birkhäuser Verlag (1987).

[4] N. KRUPNIK, On multidimensional singular integral operators in local convex spaces, Ph. D. thesis, Leningrad University (1965), (Russian).

[5] N. KRUPNIK AND MARINA MARKUS, On the inverse-closedness of some Banach subalgebras, Issledovanoia po dif. uravnenijam i mat. analizu. Kishinev, Stiinca, 1988, (93-99), (Russian).

[6] S. G. Minlin, On the index of a system of singular equations, Soviet Math. Dokl., 3 (1963), 13681371.

[7] S. G. Mikhlin, S. PrËSSdorf, Singular Integral operators, Springer-Verlag, Berlin, 1986.

[8] S. Roch, A. P. Santos, B. Silbermann, Non-commutative Gelfand Theories, Springer, (2011).

[9] A. I. VOL'PERT, The index of boundary value problems for systems of harmonic functions in three independent variables, Soviet Math. Dokl., 1 (1960), 791-793.

[10] A. I. VOLPERT, The index of systems of two-dimensional singular integral equations, Soviet Math Dokl. 3 (1962), 154, 776-777. 